\title{
Comment on the Article by Droeser et al.: 'Octreotide Prophylaxis Is Not Beneficial for Biochemical Activity and Clinical Severity of Postoperative Pancreatic Fistula after Pancreatic Surgery'
}

\author{
Markus W. Büchler \\ Department of General, Visceral and Transplantation Surgery, University of Heidelberg, Heidelberg, Germany
}

\section{Dear Editor,}

I have read with great interest the article 'Octreotide prophylaxis is not beneficial for biochemical activity and clinical severity of postoperative pancreatic fistula after pancreatic surgery' by Droeser et al. [1]

In 1996, the editor of The Lancet described surgical research as a comic opera [2], and I think this article belongs to the comic opera category.

The authors retrospectively analyzed 78 patients with a pancreatic fistula after pancreatic resection. Twenty-two of them received octreotide, and 56 served as controls without octreotide application.

In the multiple existing randomized controlled trials and systematic reviews investigating the role of octreotide in pancreatic surgery mentioned by the authors [3$8]$, octreotide was given prophylactically, i.e. before starting surgery. In the presented study, the authors administered octreotide after surgery, i.e. therapeutically. Therefore, the results of the presented study cannot be compared with the mentioned randomized controlled trials. Moreover, a current Cochrane review including 19 ran- domized trials (2,245 patients) showed a significant reduction in overall postoperative complications by $31 \%$ and a reduced fistula rate in the octreotide group. This systematic review consequently recommended preventive octreotide application for routine use in patients undergoing pancreatic resections [9]. On the other hand, Gans et al. [10] showed in their meta-analysis published in the British Journal of Surgery in 2012 that therapeutically administered octreotide in patients with existing fistula after pancreatic resections did not result in lower fistula rates. These important pieces of evidence were not discussed by the authors, which is confusing.

In table 2 of the presented article, the octreotide group had longer operations ( $\mathrm{p}<0.002)$, more blood loss $(\mathrm{p}<0.049)$, higher mortality (18 vs. $7 \%$ ), more fascial dehiscence (14 vs. $4 \%$ ), more abscess/perforations (23 vs. $9 \%$ ) and more postoperative bleeding (23 vs. $4 \%$ ) compared with controls. Therefore, in the presented study the controls are not at all comparable with the octreotide group.
The decision to apply octreotide postoperatively or not was at the discretion of the operating surgeon. It is quite obvious that patients receiving octreotide were the ones where the surgeon had a bad gut feeling after the surgery. How can one compare such patients with the controls where the surgeons felt better and more satisfied after the surgery?

The groups of this retrospective study ( 22 vs. 56 patients) are by far too small to draw any of the conclusions the authors have drawn.

This study is on 'the way back'. Clinical research in surgery has made significant progress in the last years, and meanwhile our evidence base currently develops on more and more randomized controlled trials. In contrast, the presented work tries to generate evidence by retrospectively analyzing highly biased patient data. This will and cannot work for obvious reasons.

I would also encourage the editors and reviewers of the presented work to look at table 2: apples and oranges are two different types of fruits.

\section{KARGER}

E-Mail karger@karger.com www.karger.com/dsu
C 2013 S. Karger AG, Base

0253-4886/13/0306-0328\$38.00/0 


\section{References}

-1 Droeser RA, Jeanmonod P, Schuld J, Moussavian MR, Schilling MK, Kollmar O: Octreotide prophylaxis is not beneficial for biochemical activity and clinical severity of postoperative pancreatic fistula after pancreatic surgery. Dig Surg 2012;29:484-491.

2 Horton R: Surgical research or comic opera: questions, but few answers. Lancet 1996;347: 984-985.

-3 Kollmar O, Moussavian MR, Richter S, Roi P, Maurer CA, Schilling MK: Prophylactic octreotide and delayed gastric emptying after pancreaticoduodenectomy: results of a prospective randomized double-blinded placebo-controlled trial. Eur J Surg Oncol 2008;34: 868-875.
-4 Büchler M, Friess H, Klempa I, Hermanek P Sulkowski U, Becker H, Schafmayer A, Baca I, Lorenz D, Meister R: Role of octreotide in the prevention of postoperative complications following pancreatic resection. Am J Surg 1992; 163:125-130.

5 Berberat PO, Friess H, Uhl W, Büchler MW: The role of octreotide in the prevention of complications following pancreatic resection. Digestion 1999;60(suppl 2):15-22.

6 Hesse UJ, De Decker C, Houtmeyers P, Demetter P, Ceelen W, Pattyn P, Troisi R, de Hemptinne B: Prospectively randomized trial using perioperative low dose octreotide to prevent organ related and general complications following pancreatic surgery and pancreatico-jejunostomy. Acta Chir Belg 2005; 105:383-387.

7 Li-Ling J, Irving M: Somatostatin and octreotide in the prevention of postoperative pancreatic complications and the treatment of enterocutaneous pancreatic fistulas: a systematic review of randomized controlled trials. $\mathrm{Br}$ J Surg 2001;88:190-199.
8 Suc B, Msika S, Piccinini M, Fourtanier G, Hay JM, Flamant Y, Fingerhut A, Fagniez PL, Chipponi J: Octreotide in the prevention of intra-abdominal complications following elective pancreatic resection: a prospective, multicenter randomized controlled trial. Arch Surg 2004;139:288-294.

9 Gurusamy KS, Koti R, Fusai G, Davidson BR Somatostatin analogues for pancreatic surgery. Cochrane Database Syst Rev 2013;4: CD008370.

10 Gans SL, van Westreenen HL, Kiewiet JJ, Rauws EA, Gouma DJ, Boermeester MA: Systematic review and meta-analysis of somatostatin analogues for the treatment of pancreatic fistula. Br J Surg 2012;99:754-760. 